\title{
Integralidade e cuidado a grávidas adolescentes na Atenção Básica
}

\author{
Comprehensive care of pregnant adolescents in Primary Care
}

Mônica Cecília Pimentel de Melo ${ }^{1}$

Edméia de Almeida Cardoso Coelho ${ }^{2}$

${ }^{1}$ Fundação Universidade Federal do Vale do São Francisco. Av. José de Sá Maniçoba $s / n^{\circ}$, Centro Universitário, Centro. 56304-917 Petrolina PE. monquinamelo@gmail.com ${ }^{2}$ Departamento de Enfermagem Comunitária, Escola de Enfermagem, Universidade Federal da Bahia.
Abstract Prenatal adolescent care is characterized by technical actions seeking to provide assistance from the perspective of comprehensive care. The Community Health Agent Program/Family Health Program (PACS/PSF) is a strategy for implementing the changes envisaged, which motivated this scientific investigation. The scope of the research was to assess prenatal care to pregnant adolescents by health professionals of PACS/ PSF and analyze it from the standpoint of comprehensive care. It is a qualitative study, with comprehensive care as its theoretical focus. It was conducted in PACS/PSF units in a city in the State of Bahia, and the subjects of study were the practitioners who treat pregnant adolescents. The empirical material was produced by means of semistructured interviews and non-participative observation in consultations and homecare visits and was analyzed using the speech analysis technique. This revealed that prenatal care for adolescents is provided using the biomedical model, where compliance with institutional protocols and routines takes precedence over considering the specific aspects of the adolescent. Thus it is far removed from comprehensive care, in that the practices are guided by ideological adherence to a model that fails to grant pregnant adolescents the opportunity to be treated as individuals.

Key words Pregnancy in adolescence, Prenatal care, Comprehensive care
Resumo O pré-natal em adolescentes tem se caracterizado por ações técnicas buscando-se na atualidade qualificar o cuidado na perspectiva da integralidade. O Programa de Agentes Comunitários de Saúde/Programa Saúde da Família (PACS/ PSF) constitui estratégia para avançar nas mudanças requeridas, o que motivou esta investigação científica, que teve como objetivos conhecer o processo de cuidado pré-natal a adolescentes grávidas por profissionais de saúde do PACS/PSF e analisá-lo na perspectiva da integralidade. É um estudo qualitativo, tendo a integralidade como enfoque teórico. Foi desenvolvido em unidades de PACS/PSF em um município da Bahia, sendo sujeitos do estudo profissionais que cuidam de gestantes adolescentes. O material empírico foi produzido por meio de entrevista semiestruturada e observação não participante, em consultas e visitas domiciliárias e analisado pela técnica de análise de discurso. A análise revelou que o cuidado pré-natal à adolescente se concretiza sob o modelo biomédico, e o cumprimento de rotinas e protocolos institucionais sobrepõe-se à singularidade da adolescente. Assim, distancia-se da integralidade, na medida em que as práticas são orientadas por sujeições ideológicas a um modelo que nega às adolescentes grávidas a oportunidade de serem sujeitos.

Palavras-chave Gravidez na adolescência, Cuidado pré-natal, Integralidade 


\section{Introdução}

O fenômeno da maternidade na adolescência é considerado, desde o final da década de 40 do século XX, um problema de saúde pública, intensificando-se a partir da década de 60, marco histórico de mudanças socioculturais na vida das mulheres. Dentre as conquistas femininas desse período, a dissociação entre prática sexual, casamento e reprodução a partir do acesso das mulheres aos métodos contraceptivos pode ser considerada uma das mais relevantes no processo de construção da autonomia e da liberdade reprodutiva.

Todavia, tais mudanças não foram acompanhadas por políticas públicas educacionais e de saúde direcionadas às necessidades originadas das vivências sexuais, o que colaborou para o aumento da gravidez na adolescência. Sem conhecimento do corpo e de como lidar com suas necessidades e desejos, sem informação adequada e com dificuldade de acesso aos contraceptivos, adolescentes passaram a utilizar anticoncepcionais de modo irregular e, muitas vezes, sem acompanhamento pelo serviço de saúde ${ }^{1}$.

$\mathrm{Na}$ literatura científica, constata-se uma diversidade de motivações para a gravidez na adolescência: pode emergir da vontade da adolescente a partir de um plano idealizado de ter um(a) filho(a) nessa fase da vida; para poder prender o namorado; para sair da escola ou da casa dos pais; para dar mais sentido a uma vida vazia ou por causa do desejo de querer sentir-se mais mulher ${ }^{2}$. A gestação na adolescência nem sempre é um fato equivocado, inconsequente ou danoso; inclusive, em alguns casos, pode ser resultado de um planejamento prévio consciente e decorrente da vida afetiva estável ${ }^{3}$.

Para o Ministério da Saúde, o fenômeno da maternidade na adolescência é considerado de alto risco devido às complicações biológicas e sociais para o binômio mãe e filho(a). As adolescentes com menos de 14 anos de idade têm uma probabilidade de cinco a sete vezes maior de morrer durante a gravidez do que mulheres que são mães com mais idade, e seus filhos, com frequência, nascem com peso inferior a $2.500 \mathrm{~g}$ e prematuros $^{4}$. É também entre as jovens que ocorre o maior número de abortos em condições de risco, pois muitas vezes carregadas de medo, culpa, censura, vergonha, encontram no aborto a única saída para a solução dos seus problemas. Essa decisão muitas vezes é vivida de forma solitária e clandestina ou sob pressão dos parceiros ou familiares, e ao decidirem interromper a gravidez, utilizam quaisquer recursos que tiverem à mão ${ }^{5}$.
Nos últimos anos, iniciativas governamentais se propuseram a favorecer a saúde das adolescentes. O Programa de Assistência Integral à Saúde da Mulher (PAISM), criado em 1984, valorizou a atenção à mulher em todas as fases do ciclo vital. Mas foi sobretudo o Programa de Saúde do Adolescente (PROSAD), de 1989, que deu ênfase à atenção diferenciada a esse grupo populacional nos aspectos de crescimento e desenvolvimento, sexualidade, saúde oral, saúde mental, saúde reprodutiva, saúde do estudante e prevenção de acidentes, devendo as ações correspondentes serem viabilizadas nos serviços de saúde da rede básica e hospitalar ${ }^{6}$.

No contexto atual de implementação das políticas de saúde, sobretudo com a criação do Programa de Agentes Comunitários de Saúde (PACS) e mais posteriormente o Programa de Saúde da Família (PSF), a integralidade da atenção vem sendo valorizada como eixo orientador das práticas, pois o PACS/PSF se propõe a uma reorganização da Atenção Básica, rompendo com o modelo clínico e prescritivo ${ }^{7}$.

O PACS pode ser considerado o antecessor do PSF, fornecendo elementos que tiveram um papel central na sua construção. Dentre esses elementos, ressalta-se o enfoque das ações em saúde centrado na família e não no indivíduo e o agir preventivo sobre a demanda. De certo modo, buscou-se com o PACS a adoção de uma prática não reducionista sobre a saúde das pessoas, evitando ter como eixo apenas a valorização da clínica e do ato prescritivo, propondo-se a integração com a comunidade. Desse modo, o PACS contribuiu para que o PSF se constituísse em uma estratégia de reorientação e reorganização do modelo de atenção à saúde no Brasil, um projeto dinamizador do Sistema Único de Saúde (SUS) ${ }^{8}$.

O PSF traz em sua base a preocupação em promover o acesso de grupos populacionais excluídos, voltando-se prioritariamente para os grupos sociais mais vulneráveis. Tem provocado mudanças nos principais indicadores de saúde das populações assistidas, mas tem trazido resultados pouco perceptíveis na estruturação dos serviços de saúde, sobretudo por não promover mudanças significativas no modelo assistencial ${ }^{9}$.

A intervenção na realidade sob essa ótica é facilitada pela adição de olhares dos diversos profissionais que compõem as equipes de Saúde daFamília. Assim, a integralidade ganha riqueza e expressão quando efetivada pelo PACS/PSF dentro do cenário da adolescência, na medida em que se propõe a promover uma atenção à saúde, respeitando suas especificidades e valorizando o con- 
texto em que a gravidez se insere, incluídos fatores de ordem econômica, social e cultural, em meio nos quais as relações de gênero se concretizam.

A adolescente grávida não deve ser manipulada como objeto de vulnerabilidade - risco em um contexto isolado da realidade e de suas vivências, o que implica também a sensibilização dos(as) profissionais de saúde quanto aos sentidos da integralidade, podendo assim reorientar suas práticas e escapar dos reducionismos. Desse modo, na melhoria da qualidade da atenção, inclui-se a relativização do risco divulgada na literatura obstétrica e a valorização da adolescente grávida não somente na dimensão biológica, mas em suas necessidades mais amplas, considerando-se as especificidades da faixa etária e sua singularidade.

Os(as) profissionais de saúde têm importante papel na escuta de necessidades, devendo permitir a expressão de sentimentos que emergem na vivência da gravidez de modo a se estabelecer uma relação de confiança. Evita-se, assim, que o pré-natal se torne um intercâmbio de múltiplas informações fragmentadas e imposições, pois um dos objetivos da atenção à saúde a esse grupo é possibilitar a construção de condições favoráveis para que a adolescente sinta-se acolhida e lide com as experiências da gravidez, parto e maternidade de modo favorável à sua saúde e a do(a) filho $(\mathrm{a})^{10}$.

Todavia, na concretização das políticas públicas, ainda existe escassez de ações dirigidas às especificidades desse grupo populacional, tendo predominado o caráter técnico da atenção contrariando o que é preconizado pelos programas oficiais ${ }^{11}$. Por conseguinte, faz-se necessário o redirecionamento das práticas profissionais com adolescentes grávidas, adotando-se a integralidade no cotidiano do cuidado de modo que este seja orientado pelo acolhimento, vínculo e responsabilização ante as suas demandas.

Considerando que as adolescentes grávidas constituem um grupo cada vez mais presente nos serviços de saúde, cujas especificidades requerem um cuidado mais diferenciado e que, sobretudo em áreas interioranas, a atenção destinada a esse grupo vem se desenvolvendo por meio do Programa de Agentes Comunitários de Saúde (PACS)/Programa de Saúde da Família (PSF), decidimos por uma investigação científica buscando responder à seguinte questão: como os(as) profissionais do PACS/PSF vêm concretizando as práticas de cuidado com as adolescentes grávidas? Para responder a esta questão, o estudo teve como objetivos conhecer o processo de cuidado pré-natal em adolescentes grávidas por pro- fissionais do PACS/PSF de saúde e analisá-lo na perspectiva da integralidade.

\section{Métodos}

\section{Caracterização do estudo e base teórica}

Trata-se de uma pesquisa do tipo exploratório, descritivo, com abordagem qualitativa, tendo como suporte teórico a integralidade.

A integralidade tornou-se essencial às práticas de cuidado, na medida em que se reconheceu a necessidade de superação do reducionismo que sustenta o modelo hegemônico de atenção à saúde. Busca-se, por meio dela, identificar as demandas em saúde articuladas à multidimensionalidade dos sujeitos da atenção e atender a elas ${ }^{12}$. Nessa perspectiva, o diagnóstico ganha a dimensão do cuidado distanciando-se do ato prescritivo, centrado no biológico e impulsionado pelo complexo médico industrial. As ações de cuidado são permeadas pelo diálogo, escuta, acolhimento, vínculo, acesso, responsabilização com qualidade formal e política ${ }^{13}$.

A integralidade não despreza o exercício da clínica, mas valoriza o seu uso prudente com a visão das necessidades outras dos sujeitos, com respostas aos problemas de saúde específicos ou que afligem certo grupo populacional, considerando os contextos socioculturais. Busca compreender as necessidades dos sujeitos como ato terapêutico que extrapola o sofrimento apresentado pelos indivíduos, o que implica responsabilidade de uma equipe atuante que se integra para superar contradições estruturais dos processos de trabalho, da organização dos serviços e das práticas em saúde ${ }^{14}$.

No âmbito da saúde da mulher, busca-se qualificar o cuidado oferecendo-se o máximo de bem-estar à pessoa usuária, do ponto de vista de suas necessidades, de seus direitos humanos, de sua experiência e do fortalecimento do poder sobre si mesma ${ }^{15}$. Assim, orientamos nosso olhar pela integralidade, defendendo-a como a concretização de práticas de atenção que garantam o acesso das mulheres a ações resolutivas construídas segundo as especificidades do ciclo vital feminino e do contexto em que as necessidades são geradas. Nesse sentido, o cuidado deve ser permeado pelo acolhimento com escuta sensivel de suas demandas valorizando-se a influência das relações de gênero, raça/cor, classe e geração no processo de saúde e de adoecimento das mulheres ${ }^{16}$. 


\section{Trajetória metodológica}

A pesquisa foi desenvolvida em uma cidade do interior da Bahia, local em que a Atenção Básica à saúde da população é prestada por meio de duas equipes de saúde do PSF e duas do PACS, áreas em que a cobertura por ACS atinge $100 \%$ do número previsto para o atendimento às famílias.

Foram adotados como critérios de inclusão: atuar profissionalmente na comunidade há mais de três anos, tempo considerado adequado à realização de cursos de capacitação para o trabalho em saúde, segundo os princípios desses programas; desenvolver atividades de atenção pré-natal a grávidas adolescentes por meio de consultas, atividades educativas e/ou visitas domiciliárias; e aceitar participar no estudo.

Os sujeitos do estudo foram duas enfermeiras, uma do PACS e outra do PSF; uma médica do PSF e cinco agentes comunitários de saúde (ACS) do quadro de servidores do PACS ou PSF, totalizando oito profissionais que acompanhavam gestantes adolescentes na zona urbana no período da pesquisa, 19/05/2006 a 04/07/2007. Os(as) profissionais participantes do estudo tinham entre trinta a cinquenta anos de idade e tempo de trabalho de cinco a dezesseis anos. Todos(as) realizaram capacitações preconizadas para atuação no PACS/PSF, nestas incluídas: Cartão SUS, Curso Introdutório ao PSF, Capacitação em Saúde do Idoso, Hiperdia (hipertensão e diabetes), tuberculose, hanseníase, Mais Saúde Bahia, DST/HIV/Aids, raiva humana, dengue, imunização e vigilância ambiental. Estas foram diversificadas entre os(as) profissionais; apenas uma enfermeira fez capacitação em saúde reprodutiva.

Inicialmente, foi solicitado autorização através de ofício à Secretaria Municipal de Saúde. Neste, foi comunicado ser a pesquisa parte de um estudo mais amplo financiado pelo Conselho Nacional de Desenvolvimento Científico e Tecnológico (CNPq), sendo anexado documento de aprovação pelo Comitê de Ética em Pesquisa da Secretaria de Estado da Saúde da Bahia. Uma vez autorizado o estudo, foram feitos contatos com os profissionais técnicos e com a secretária municipal de saúde, havendo participação em reuniões com os ACS. Nessas ocasiões, foi feito o convite para participação na pesquisa mediante apresentação dos objetivos, sendo agendados dias de entrevistas, de observações de consultas e visitas domiciliárias com os(as) que se disponibilizaram a participar. Todos(as) assinaram o Termo de Consentimento Livre e Esclarecido, elaborado segundo os critérios da Resolução n 196/96 do Conselho Nacional de Saúde.

O material empírico foi produzido por meio da técnica de observação não participante e não estruturada e entrevista semiestruturada. As entrevistas foram conduzidas através da utilização de um gravador, após prévia autorização dos(as) entrevistados(as).

O estudo compreendeu dois momentos. No primeiro momento, foi utilizado um roteiro de observação não participante e não estruturada. A observação foi realizada durante as consultas médicas e de enfermagem com gestantes adolescentes em qualquer idade gestacional e durante as visitas domiciliárias dos ACS. No segundo momento, foram realizadas as entrevistas de todos(as) os(as) profissionais da equipe de saúde do PACS/PSF, participantes do estudo. Havia pretensão de utilizar a observação também em processos educativos com grupos de adolescentes, mas, não havendo tal atividade nos serviços por ocasião da pesquisa, foi inviabilizada.

O material empírico foi analisado pela técnica da análise de discurso segundo Fiorin ${ }^{17}$. O autor considera que análise de discurso é uma prática e um campo da linguística e da comunicação especializada em analisar construções ideológicas presentes em um texto, sendo este um objeto individual e um todo organizado de sentidos, num determinado universo de significação. O discurso é uma posição social cujas construções ideológicas são materializadas na linguagem, sendo revelada pela análise a visão de mundo dos sujeitos enunciadores. Isso significa que todo discurso é uma construção social, não individual, e só pode ser analisado considerando-se seu contexto histórico-social.

Para operacionalização dessa técnica, foram seguidas as etapas propostas pelo autor: realizar leituras de todo o texto para localizar os elementos concretos e abstratos que conduzam a um mesmo bloco de significados; agrupar as informações de acordo com os elementos significativos (concretos e abstratos) que se somam ou se confirmam num mesmo plano de significados; depreender os temas centrais para a formulação de categorias empíricas a serem analisadas em articulação com o eixo teórico e a literatura pertinente. Nesta comunicação, é apresentada uma das categorias do estudo. 
lidades de universalizar o cuidado à saúde, uma vez que as equipes têm sido implantadas, prioritariamente, em locais cujas comunidades apresentam limitação de acesso aos serviços de saúde, tendo como princípios orientadores a integralidade, a equidade e a participação social. O trabalho em equipe constitui-se em uma das premissas do PSF para a produção de impactos sobre os diferentes fatores que interferem no processo saúde-doença ${ }^{18}$.

Todavia, a ampliação do número de equipes como um fenômeno isolado de expansão assistencial não garante por si só a construção de um novo modelo; é preciso também uma mudança nas bases de formação dos profissionais ${ }^{19}$. Assim, a estruturação do trabalho em equipes multiprofissionias no PSF, isoladamente, não garante uma ruptura com a dinâmica biomédica. Há necessidade de dispositivos que alterem o processo do trabalho em saúde, nos fazeres cotidianos de cada profissional, identificando-se os elementos que configurariam uma nova lógica no agir desses profissionais e na forma como se produz o cuidado em saúde ${ }^{20}$.

No tocante à atenção às adolescentes, particularizadas neste estudo pelo cuidado pré-natal na perspectiva da integralidade, os(as) profissionais de saúde devem acolher as grávidas adolescentes com escuta sensível e responsabilização diante das especificidades das demandas, valorizando o contexto em que estas são geradas. O movimento dialético identificado na análise dos discursos de profissionais do PACS/PSF participantes do estudo trouxe simultaneamente aproximações e distanciamentos da perspectiva da integralidade. Em se tratando do cuidado pré-natal a esse grupo, apresentaram-se no mesmo sujeito modos de perceber e modos de agir discordantes, assim como são identificadas falas e práticas que se confirmam segundo o modelo clínico.

Diante do questionamento aos profissionais sobre como procediam para atender às necessidades de adolescentes grávidas por cuidado à saúde, a análise dos discursos das enfermeiras revelou posições sociais que trazem subjacente um modo de perceber a gravidez na adolescência valorizando-a como algo possível no ciclo vital feminino que, embora ocorrendo em meio a adversidades, traz consigo possibilidades de enfren- tamentos, amadurecimento e convivência. Esse processo é facilitado quando as ações de saúde são direcionadas pelo respeito à singularidade, $o$ que pode ser constatado nos depoimentos.

Olha, o que eu tento fazer é sentar com calma com elas, dispor de um grande tempo para conversar pra conquistar essa confiança, pra ela ter condições de se abrir, pra depois que eu tiver conhecimento de toda a vida dela, aí, eu tentar ajudar em termos de orientação. [...] e a adolescente, se não for bem tratada, respeitando, sim, a individualidade da paciente, ela não vem mais. O objetivo nosso é que ela seja acompanhada do início ao final, durante e depois da gravidez (Enf 1/PSF).

Em outro momento, a Enf 2/PACS acrescenta ser necessário conhecer o contexto em que a adolescente vivencia a gravidez, afirmando ser importante saber como foi que aconteceu essa gravidez, como que ela foi recebida. Acho que isso é importante. Se a família tá acolhendo, se está tendo contato com aquele parceiro. Algumas referem que o parceiro está dando apoio, às vezes não está naquele relacionamento estável, mas que ele paga os exames, que ele tá procurando saber como é que tá a gravidez. Então, eu me prendo muito como é que está acontecendo essa gravidez na vida delas, a relação em si com o parceiro (Enf 2/PACS).

Os discursos que revelam uma abordagem politicamente coerente com uma visão mais ampliada do fenômeno da gravidez na adolescência não se concretizaram na análise das observações da consulta de enfermagem a essas usuárias. Nesta, a adolescente é abordada de modo impessoal e distante de uma relação entre sujeitos, sendo a consulta orientada pelo modelo normativo, em que o cumprimento de protocolos institucionais se sobrepõe às especificidades da adolescência e da gravidez nesta fase. A dissociação entre o modo de perceber a gravidez na adolescência e a prática concreta revela a manutenção da hegemonia do modelo biomédico e a dificuldade de profissionais inscreverem nos atos de cuidado a dimensão política transformadora dos processos relacionais na atenção à saúde. Lê-se no relato de observação:

A adolescente entra no consultório, é uma consulta subsequente. Ninguém se cumprimenta. A enfermeira questiona se já fez os exames, e a gestante confirma de cabeça baixa. Pede os resultados, sendo informado estarem normais. Verifica a PA, o peso e faz o exame físico com ênfase nas condições das mucosas, altura uterina e batimentos cardiofetais (BCF). Informa à adolescente que está tudo normal e faz os registros no cartão e na ficha perinatal, que não contém uma folha para registro da 
evolução. A adolescente é orientada quanto ao sono, alimentação e ingesta hídrica. A enfermeira faz o registro e de cabeça e voz baixas informa a data provável do parto (DPP). Em seguida, esclarece sobre a vacina antitetânica e informa que estará na comunidade, na semana seguinte, realizando vacinação. Afirma: "Quero ver você lá!" Preenche o cartão da gestante. Orienta o preparo das mamas para lactação. A adolescente afirma estar sentindo "escorrimento" e a profissional solicita um papanicolaou, sem ter sido levantada a história das suas queixas vaginais e da vivência sexual. É dito que o retorno será informado pelo ACS (Enf 1/PSF).

$\mathrm{O}$ discurso médico originário da entrevista e da observação, apresentado a seguir, operacionaliza outro aspecto da fragmentação do cuidado na medida em que o acompanhamento da gravidez em seu processo fisiológico aparece como responsabilidade exclusiva da enfermeira, além de direcionar seu olhar por abordagem eminentemente técnica. Ao referir-se à atenção à adolescente, afirma:

Faço o que dá pra fazer. É atender, verificar o cartão, verificar a DUM, a DPP... Na verdade, a enfermeira é quem fica com esta parte. Enquanto equipe, a gente trabalha dividindo os programas. Eu atendo mais as intercorrências, então não tenho tanto contato com as adolescentes (Med 1/PSF).

O conteúdo resultante da observação da consulta médica é relatado a seguir:

A adolescente é chamada, entra, senta, não há cumprimentos, é a primeira consulta médica, a adolescente já está sob acompanhamento da enfermeira. A profissional pergunta sobre os exames, se é a primeira gravidez, solicita a data da última menstruação, calcula a data provável do parto $e$ confirma com a adolescente se está no $5^{\circ}$ mês. Questiona sobre queixas e movimentos fetais. Pergunta novamente sobre queixas da gravidez: "Tem certeza que não está sentindo nada?" A adolescente confirma não ter queixas. A médica verifica o peso e a pressão arterial. Não informa o valor à adolescente. Preenche o cartão da gestante e a ficha perinatal. Nada é falado! Tudo é imediatamente anotado. Em silêncio, realiza o exame físico obstétrico. Orienta sobre alimentação e uso de sulfato ferroso. Entrega o cartão da gestante. Na ficha perinatal, não há registro de evolução. Afirma que no retorno será atendida pela enfermeira (Med 1/PSF).

No setor saúde, a impessoalidade com que os(as) profissionais atuam, a despersonalização dos(as) usuários(as) e a substituição de uma relação dialógica por exames e procedimentos trans- formam esse setor em produtor de violência contra as pessoas. Frequentemente, os serviços e seus profissionais são vítimas, mas principalmente são atores de violência e precisam ter consciência de que contribuem para que as pessoas sintam medo e vergonha dos serviços. Esse fenômeno é observado predominantemente com pessoas de baixo poder aquisitivo, sendo demonstrado a elas insensibilidade, discriminação e negligência de cuidados $^{21}$. Desse modo, a supremacia do modelo clínico promove ações de descuidado por uma lógica da produção dos(as) cuidadores(as) baseada em procedimentos técnicos sem ação integralizada e unificada em torno do(a) usuário(a ${ }^{22}$.

Coelho ${ }^{23}$ constatou, em pesquisa com enfermeiras que cuidam de mulheres, que grávidas adolescentes muitas vezes se apresentam ao serviço de saúde em situação de desamor, desamparo e dor, mas ao se sentirem acolhidas por essas profissionais se vinculam a elas construindo relação de confiança. Todavia, a minimização dos problemas é dificultada na medida em que a experiência da gravidez é descontextualizada e a solução reside em aceitar a realidade sem questioná-la, estando implícito no discurso profissional o padrão normativo da família nuclear em que a gravidez e a maternidade são idealizadas segundo convenções sociais naturalizadas.

Assim, a realidade dos serviços de saúde tem mostrado que nem sempre a produção das ações dos(as) cuidadores(as) está comprometida efetivamente com atos terapêuticos do cuidar. Busca-se, na atualidade, construir alternativas para a organização das práticas de atenção à saúde no Brasil, em que o cuidado aparece como uma atitude terapêutica, centrado em movimentos de humanização, de valorização da escuta, demonstrado no interesse em ouvir o(a) outro(a), pois ouvir e fazer-se ouvir são polos indissociáveis de qualquer legítimo diálogo ${ }^{24}$.

A avaliação clínica é necessária e imprescindível ao desenvolvimento saudável da gestação, ressaltando-se que a vigilância a essa dimensão da saúde torna-se um instrumento de proteção ao binômio mãe-filho(a) e fator de segurança ante as possibilidades de complicações no ciclo gravídico-puerperal. A clínica, porém, não se sustenta como balizadora das práticas em saúde quando se busca a superação do modelo biomédico e se vislumbra um cuidado na perspectiva da integralidade, em que a escuta, o vínculo e a responsabilização constituem uma tríade indissociável da dimensão biológica. 


\section{Práticas de Agentes Comunitários em Saúde reproduzindo a hegemonia do modelo técnico}

Os depoimentos de alguns ACS referentes ao questionamento sobre sua atuação profissional no sentido de atender às necessidades das adolescentes grávidas da comunidade revelaram que suas ações se apoiam no modelo técnico, embora tenham se inserido no PACS/PSF em um momento histórico de mobilização para transição paradigmática.

Geralmente o que eu olho é a TA e o peso pra orientar. Já até falei com elas na visita, na semana, que elas comem muito. Ai eu falo que tem que ter cuidado, tem que controlar. Controlar a alimentação! É! Dividir, fracionar a alimentação. Olho o cartão, se já começou a fazer os exames, quando é a próxima consulta. Eu pego no pé delas porque é muito importante, se não relaxam (ACS 3/PACS).

Em outros depoimentos, agentes comunitários revelam a possibilidade de construir relação de confiança, disponibilizando-se para a escuta e a formação de vínculos. A interseção entre a dimensão expressiva e instrumental do cuidado mostra-se possível nessas práticas, o que se constata nos discursos do ACS 3 e do ACS 4. Estes convivem com a posição social em que o movimento de aproximação com as necessidades das adolescentes traz consigo a contradição, ao ser revelado no discurso do ACS 1 o poder profissional, tema central no modelo biomédico. Assim, lê-se em seus depoimentos:

É, faço o que é da rotina. Visito, pergunto se tá tudo bem, se tá precisando de alguma coisa, às vezes querem só desabafar, conversar sobre o namorado, tirar dúvida, perguntar se pode comer isso ou aquilo. Olho o cartão da vacina, cadastro as gestantes novas e falo dos cuidados da gravidez porque a gente já teve treinamento (ACS 4/PSF).

Eu falo pra elas que não escondam, pois tudo que sentir durante a gravidez tem que conversar comigo. Se ela não quiser conversar com a doutora, eu peço para que converse comigo que aí eu passo pra ela (ACS 1/PACS).

No depoimento do ACS 1, há uma relação de intimidação e desvalorização do direito à confidencialidade da adolescente, ainda que seja orientado por boas intenções. Compreendendo-se como sujeito da atenção que não detém o conhecimento técnico-científico na área obstétrica, compromete seu papel de interlocutor entre comunidade e serviço quando impõe a fala e assume transmiti-la àquela com quem a adolescente certamente não construiu relação de confiança e por isso se distancia, não expondo seus problemas.

As relações que abrem possibilidades para a construção de vínculos, embora paradoxais, intercruzam-se com a posição social em que a gravidez na adolescência é considerada como algo que ideologicamente define para as jovens mães uma vida de exclusão, sendo essas consideradas pelo ACS 5 como incapazes de construir responsabilidade, assim apresentando-se:

Eu sempre oriento, né? Mas entra num ouvido e sai pelo outro. Eu morro de falar. Mas faço tudo que tá dentro de nossa obrigação fazer. É olhar o cartão de gestante, de vacina, ver o peso pra não engordar demais, oriento sempre alimentação e pergunto se tem alguma dúvida, que sempre tem! Não sabem cuidar nem delas próprias, quanto mais cuidar de filho! Eu tenho pena é da mãe que vai arcar com tudo, mas o que se pode fazer? (ACS 5/PACS).

Nas observações de visitas domiciliárias, o modelo biomédico se confirmou como eixo norteador de suas práticas. No tocante ao ACS 5, este se orienta por uma lógica que faz do espaço profissional a sua própria casa, agindo segundo valores que contrariam a ética em saúde e a ética da integralidade, sem considerar a singularidade da adolescente visitada, que vivencia a gravidez em um contexto que a faz ter vulnerabilidade social, econômica e emocional. Seu discurso se confirma por ocasião da visita domiciliária:

A casa da adolescente é feita de madeira e o chão é de terra. A adolescente nos recebe com a mãe do lado, uma senhora na maturidade. A ACS abordou a adolescente grosseiramente: "Pra que escondeu? Agora vai fazer o pré-natal tarde!" A adolescente ficou assustada com o tom de voz da ACS. A ACS procura saber se a adolescente já iniciou o pré-natal e olhou em seguida o cartão da gestante. Procura saber também sobre o cartão da vacina, e a adolescente disse que perdeu. Mas quando sua mãe se afasta, afirma que o seu cartão foi rasgado pela mãe quando procurava dinheiro em sua bolsa para seu padrasto beber, pois ele bate em sua mãe se não tiver o dinheiro para a bebida. A ACS fica assustada e procura terminar logo a visita, pois o padrasto da adolescente é usuário de drogas [a ACS comenta com a pesquisadora]. A ACS ficou responsável em marcar os exames da adolescente e a orientou rapidamente sobre alimentação, aleitamento materno e a vacina antitetânica (ACS 5/PACS).

O modo como a atenção é oferecida pelos ACS às adolescentes grávidas leva a um distanciamen- 
to destas do serviço de saúde, porque são destituídas de condições que respeitem sua singularidade. No tocante ao ACS 5, encontram-se elementos nos textos analisados que trazem subjacente a representação da gravidez na adolescência como transgressão dos padrões morais e o serviço de saúde como lugar onde se ditam ordens que têm força de lei. É preciso ter cautela, pois lidar com adolescentes é saber lidar com suas vivências e experiências, entendendo que os(as) mesmos(as) não constituem uma massa homogênea de interesses, mas um conjunto de individualidades em interações não isentas de conflitos e contradições ${ }^{25}$.

Ante a proposta do PSF, nos discursos analisados predominam o monólogo tecnocrata, a unilateralização de saber e a imposição deste em detrimento da valorização da singularidade da adolescente. As preocupações de ordem técnica, também necessárias ao cuidado, buscam mudanças de comportamento da grávida adolescente se sobrepondo ao conjunto de necessidades presentes, mas não investigadas na relação estabelecida. Considerada incapaz de construir e assumir responsabilidades, a grávida adolescente é colocada como espectadora no cenário do cuidado à saúde, negando-se a oportunidade de se tornar sujeito ativo nesse processo.

\section{Considerações finais}

As ações concretas de cuidado às adolescentes grávidas se revelaram como um trabalho profissional orientado pelo modelo biomédico, em que as ações de saúde concentram-se essencialmente na clínica, distanciando-se das necessidades mais amplas das adolescentes. Ao inserir-se no PSF ou PACS, os(as) profissionais de saúde realizam capacitações para atuação segundo os princípios do programa, mas, certamente, com formação em saúde orientada pelos padrões hegemônicos, as práticas não apontam para a mudança do modelo de atenção.

No estudo, há modos divergentes de pensar o fenômeno da gravidez na adolescência, mas na prática todos operacionalizam suas ações com base tecnicista, de modo que o cumprimento de rotinas e protocolos institucionais se sobrepõe à singularidade da adolescente grávida. Portanto, o cuidado pré-natal à adolescente distancia-se da perspectiva da integralidade, na medida em que os(as) profissionais, embora inseridos(as) em programas que valorizam as relações de cuidado, mantêm-se presos às bases de formação, orientadas por sujeições ideológicas a um modelo que nega às adolescentes grávidas a oportunidade de serem sujeitos.

Faz-se necessário inserir no cotidiano do cuidado processos educativos grupais que ofereçam suporte para que adolescentes desenvolvam habilidades para a vida, tais como negociação, comunicação, resolução de conflitos e tomada de decisões. Para isso, o(a) profissional deve ser capacitado(a) a desenvolver ações que incentivem a autonomia dos(as) jovens, criando um ambiente de compreensão e aceitação mútua, para que os(as) participantes encontrem respostas positivas às necessidades de segurança, de reconhecimento e de aceitação ${ }^{26}$.

Assim, incentivar as adolescentes grávidas a serem sujeitos deve fazer parte de um pré-natal que valorize os sentidos da integralidade - necessidades essas que envolvem apoio às suas vivências como mulheres e mães; compreensão das diferentes formas de expressão de sua sexualidade; facilitação do acesso à informação e aos métodos contraceptivos com garantia de acompanhamento clínico; respeito às jovens com garantia de atenção em situação de abortamento; garantia de acesso ao pré-natal e à maternidade segura por meio de profissionais capacitados(as) e sensibilizados(as) para os processos de vida, valorizando os condicionantes de gênero nas experiências femininas.

Nesse sentido, conformar práticas de assistência que resumem a gravidez na adolescência a processos descontextualizados constitui um descaminho à atenção integral. A integralidade pressupõe inovações nas práticas de saúde em diferentes cenários, trazendo uma perspectiva reflexiva de valorização dos sujeitos, havendo necessidade de uma reconstrução ética e política do cuidado à saúde das grávidas adolescentes na realidade estudada. 


\section{Colaboradores}

MCP Melo participou da elaboração do projeto, revisão de literatura, produção do material empírico, análise dos resultados e redação do artigo; EAC Coelho, da elaboração do projeto, análise dos resultados, redação e revisão do artigo.

\section{Referências}

1. Coelho EA. Enfermeiras que cuidam de mulheres: conhecendo a prática sob o olhar de gênero [tese]. São Paulo: Universidade de São Paulo; 2001.

2. Godinho RA, Schelp JRB, Parada CMGL, Bertoncello NMF. Adolescentes e grávidas: onde buscam apoio? Ver Latino Am Enferm 2000; 8(2):25-32.

3. Belo MAV, Silva JLP. Conhecimento, atitude e prática sobre métodos anticoncepcionais entre adolescentes gestantes. Rev Saude Publica 2004; 38(4): 479-487.

4. Brasil. Ministério da Saúde. Secretaria de Atenção à Saúde. Saúde integral de adolescentes e jovens: orientações para a organização de serviços de saúde. Brasília: Ministério da Saúde; 2005. (Série A. Normas e Manuais Técnicos).

5. Souza VLC, Corrêa MSM, Souza SL, Bezerra SA. O aborto entre adolescentes. Rev Latino Am Enferm 2001; 9(2):42-47.

6. Brasil. Ministério da Saúde. Secretaria Nacional de Programas Especiais de Saúde. Programa Saúde do Adolescente: bases programáticas. Brasília: Ministério da Saúde; 1989.

7. Franco TB, Merhy EE. Programa Saúde da Família (PSF): contradições de um programa destinado à mudança do modelo tecnoassistencial. In: Merhy EE, Magalhães Júnior HM Rimoli J, Franco TB, Bueno WS, organizadores. O trabalho em saúde: olhando e experienciando o SUS no cotidiano. $2^{\mathrm{a}}$ ed. São Paulo: Hucitec; 2004. p. 150-157.

8. Alves VS. Um modelo de educação em saúde para o Programa Saúde da Família: pela integralidade da atenção e reorientação do modelo assistencial. Interface - Comun, Saúde, Educ 2004/2005; 9(16):39-52.

9. Senna MCM. Eqüidade e política de saúde: algumas reflexões sobre o Programa Saúde da Família. Cad Saude Publica 2002; 18(Supl.):203-211.

10. Bahia. Secretaria de Saúde. Saúde reprodutiva: manual para prestação de serviços. Salvador: Secretaria de Saúde do Estado da Bahia; 1998.

11. Santos AA, Freire ALC, Melo MCP, Ribeiro RA, Costa SMF. Aspectos legais do atendimento da(o) enfermeira (o) à adolescente grávida [monografia]. Salvador: Universidade do Estado da Bahia; 2005.

12. Mattos RA. Os sentidos da integralidade: algumas reflexões acerca de valores que merecem ser defendidos. In: Pinheiro R, Mattos RA, organizadores. Os sentidos da integralidade na atenção e no cuidado à saúde. Rio de Janeiro: Uerj, IMS, Abrasco; 2001. p. 39-64

13. Franco TB, Magalhães Júnior HM. Integralidade na assistência a saúde: organização das linhas de cuidado. In: Merhy EE, Magalhães Júnior HM, Rimoli J, Franco TB, Bueno WS. O trabalho em saúde: olhando e experienciando o SUS no cotidiano. $2^{\text {a }}$ ed. São Paulo: Hucitec; 2004. p. 37-54.

14. Mattos RA. Os sentidos da integralidade: algumas reflexões acerca de valores que merecem ser defendidos. In: Pinheiro R, Mattos RA, organizadores. Os sentidos da integralidade na atenção e no cuidado à saúde. Rio de Janeiro: Uerj, IMS, Abrasco; 2001. p. 39-64.

15. Rede Feminista de Saúde. Adolescentes, saúde sexual, saúde reprodutiva: dossiê. Belo Horizonte: Rede Feminista de Saúde; 2004. 
16. Coelho EAC, Oliveira JF, Almeida MS, Silva CTO, Sena VC. Integralidade do cuidado à saúde da mulher: limites e possibilidades na atenção básica: relatório técnico CNPq. Salvador: CNPq; 2007.

17. Fiorin JL. Linguagem e ideologia. $2^{\text {a }}$ ed. São Paulo: Ática; 2003.

18. Araújo MBS, Rocha PM. Trabalho em equipe: um desafio para a consolidação da Estratégia Saúde da Família. Cien Saude Colet 2007; 12(2):455-464.

19. Paim JS. Modelos de atenção e vigilância da saúde. In: Rouquayrol MZ, Almeida Filho N, organizadores. Epidemiologia e saúde. $6^{\text {a }}$ ed. Rio de Janeiro: medsi; 2003. p. 567-586.

20. Araújo MBS, Rocha PM. Trabalho em equipe: um desafio para a consolidação da Estratégia Saúde da Família. Cien Saude Colet 2007; 12(2):455-464.

21. Minayo MCS. A violência faz mal à saúde individual e coletiva: textos básicos do Curso de Educação à Distância da Ensp sobre violência e saúde. [acessado 2007 abr 8]. Disponível em: http://www.ensp.fiocruz.br/ forumviolencia/arquivos/arq14.pdf

22. Merhy EE. Ato de cuidar: a alma dos serviços de saúde. In: Brasil. Ministério da Saúde. Secretaria de Gestão do Trabalho e da Educação na Saúde. Ver-SUS Brasil: caderno de textos. Brasília: Ministério da Saúde; 2004. p. 108-137. (Série B. Textos Básicos de Saúde).

23. Coelho EA. Enfermeiras que cuidam de mulheres: conhecendo a prática sob o olhar de gênero [tese]. São Paulo: Universidade de São Paulo; 2001.

24. Ayres JRCM. O cuidado, os modos de ser (do) humano e as práticas de saúde. Saúde e Soc 2004; 13(3):16-29.

25. Ayres JRCM, França Júnior I. Saúde do adolescente. In: Schraiber LB, Nemes MIB, Gonçalves RBM, organizadores. Saúde do adulto: programas e ações na unidade básica. 2a ed. São Paulo: Hucitec; 2000. p. 66-108.

26. Brasil. Ministério da Saúde. Secretaria de Atenção à Saúde. Saúde integral de adolescentes e jovens: orientações para a organização de serviços de saúde. Brasília: Ministério da Saúde; 2005. (Série A. Normas e Manuais Técnicos).

Artigo apresentado em 07/10/2008

Aprovado em 24/04/2009

Versão final apresentada em 30/05/2009 